\title{
STUDI TENTANG HUBUNGAN ANTARA JUMLAH MODAL DENGAN JUMLAH SHU DI KPN "KELUARGA SEHATI" SMKN - 2 PALANGKARAYA TAHUN 2008-2013
}

\author{
IIN NURBUDIYANI
}

Dosen Pada Fakultas Keguruan dan IImu Pendidikan Universitas Muhammadiyah Palangkaraya

\begin{abstract}
This study aimed to find out: (1) the increase of capital in KPN Keluarga Sehati SMKN-2 Palangkaraya 2008-2013; (2) The increase of SHU in KPN Keluarga Sehati SMKN-2 Palangkaraya 20082013; (3) is there any correlation between capital enhancement to SHU in KPN Keluarga Sehati SMKN-2 Palangkaraya 2008-2013. The population were all committee members and staffs. The data were data primer (transaction posts in final income which has correlation to capital enhancement and SHU). Data secondary data (the committee report in the final period income which has correlation to capital enhancement and SHU. This study used interview and documentation. Data analysis used two steps: calculation and finishing technique of data analysis used product moment Karl Pearson, and to analyze the correlation degree and to compare the correlation gained or identified " $r$ ". if " $r$ " is bigger than $r$ critic it is significant. The significant score automatically reject Ho accepted $\mathrm{Hi}$, based on the significant level $5 \%$. Involve in "r" product moment. the result described as following: (1) the capital enhancement in KPN Keluarga Sehati SMKN-2 Palangkaraya in 2008-2013 increased in each year; (2) the enhancement income in KPN Keluarga Sehati SMKN-2 Palangkaraya in 2008-2013 increased and decreased each year; (3) the correlation between capital enhancement and income enhancement in KPN Keluaraga sehati SMKN-2 Palangkaraya has no correlation, it caused of the committee prior is to welfare members than profit.
\end{abstract}

Key words: study, correlation, capital, net income

\begin{abstract}
ABSTRAK
Penelitian ini bertujuan untuk mengetahui: (1) Perkembangan jumlah modal di KPN Keluarga Sehati SMKN-2 Palangkaraya Tahun 2008-2013; (2) Perkembangan jumlah SHU di KPN Keluarga Sehati SMKN-2 Palangkaraya Tahun 2008-2013; (3) Apakah ada hubungan antara perkembangan jumlah modal dengan perkembangan jumlah SHU di KPN Keluarga Sehati SMKN-2 Palangkaraya Tahun 2008-2013. Populasi dalam penelitian ini adalah seluruh pengurus ditambah dengan karyawan. Data yang diperlukan adalah, data primer (pos-pos transaksi dalam neraca akhir yang ada hubungannya dengan jumlah perkembangan modal dan sisa hasil usaha), dan data sekunder (laporan-laporan pengurus pada akhir periode mengenai neraca akhir yang berkaitan dengan perkembangan jumlah modal dan sisa hasil usaha). Penelitian menggunakan dua macam teknik pengumpulan data yaitu: intervieu dan dokumentasi. Analisa data atau pengolahan datanya menggunakan dua tahap yaitu: tahap perhitungan dan tahap penyelesaian. Teknik analisa yang dipakai adalah teknik product moment dari Karl Pearson, sedangkan pengolahan derajad korelasinya dengan perbandingan antara korelasinya yang diperoleh atau yang dicari " $r$ ". Bilaman " $r$ " lebih besar dari nilai r kritik maka signifikan. Dengan nilai signifikan kita akan menolak Ho dan menerima $\mathrm{Hi}$, yang didasarkan atas taraf signifikansi sebesar $5 \%$ yang terdapat dalam tabel nilai ' $r$ " product moment. Hasil penelitian adalah sebagai berikut: (1) Perkembangan modal di KPN Keluarga Sehati SMKN-2 Palangkaraya, mulai tahun 2008-2013 mengalami kenaikan pada tiap-tiap tahunnya; (2) Perkembangan sisa hasil usaha di KPN Keluarga Sehati SMKN-2 Palangkaraya, mulai tahun 2008-2013 mengalami kenaikan dan penurunan pada tiap-tiap tahunnya; (3) Hubungan antara perkembangan jumlah modal dengan perkembangan jumlah sisa hasil usaha di KPN Keluarga Sehati SMKN-2 Palangkaraya tidak ada hubungannya, ini dikarenakan pengurus lebih mengutamakan kesejahteraan anggota dari pada mencari keuntungan.
\end{abstract}

Kata kunci : studi, hubungan, modal, sisa hasil usaha (SHU) 


\section{PENDAHULUAN}

Pembangunan ekonomi nasional adalah untuk meningkatkan kesejahteraan sosial dan kemakmuran rakyat banyak bukan untuk orang perorangan maupun golongan. Di dalam UndangUndang Dasar 1945 pasal 33 ayat 1, dijelaskan bahwa "Perekonomian di Indonesia disusun sebagai usaha bersama berdasarkan asas kekeluargaan". Sehingga sesuai dengan pasal tersebut menunjukkan adanya suatu sistem demokrasi ekonomi yang tercermin dalam tata perekonomian Indonesia. Adapun tata perekonomian di Indonesia meliputi tiga sektor yaitu: sektor Negara, sektor swasta, dan koperasi. Sedang bentuk perusahaan yang sesuai dengan asas kekeluargaan tersebut adalah koperasi. Untuk itu koperasi adalah merupakan bagian yang penting dalam pembangunan perekonomian yang diharapkan mampu menjadi soko guru perekonomian dan tulang punggung ekonomi bangsa. Di samping itu juga koperasi diharapkan dapat berfungsi sebagai alat perjuangan ekonomi untuk mempertinggi kesejahteraan rakyat, alat pendemokrasi ekonomi dan urat nadi perekonomian bangsa.

Keberhasilan dalam usaha koperasi bukan merupakan suatu masalah yang mudah dan ringan, karena banyak faktor yang menjadi penghambat. Salah satu faktor tersebut adalah faktor modal, karena dari adanya modal inilah kegiatan usaha koperasi dapat berjalan dan berkembang, dengan pengertian memperhatikan modal dengan tidak mengesampingkan kepentingan anggotanya, seperti yang dijelaskan dalam buku koperasi Indonesia yang berdasarkan Pancasila sebagai berikut:
Koperasi adalah sebagai alat sosial dan alat ekonomi haruslah menjalankan usaha (bisnis) dengan demikian modal mempunyai kedudukan fital tetapi dengan pengertian modal tersebut tidak boleh diberi arti yang paling penting dari pada kepentingan anggotanya (Karta Saputra, 2009: 164).

Modal koperasi dikumpulkan dari simpanansimpanan anggota sebagai modal utama koperasi. Biasanya simpanan tersebut tidak cukup besar, mengingat keadaan ekonomi para anggota pada umumnya lemah, dengan demikian dapat dikatakan bahwa modal usaha yang relatif kecil maka volume usaha juga terbatas, sehingga akan mendapatkan sisa hasil usaha yang relatif kecil juga. Agar dapat meningkatkan usahanya dan memperoleh sisa hasil usaha yang lebih besar, koperasi harus menyusun rencana kerja yang baik. Salah satu dari rencana tersebut dapat berupa pengembangan atau penambahan modal dan bagaimana kebijaksanaan pengurus dalam meningkatkan jumlah modalnya agar koperasi dapat berkembang dan maju, meskipun pada dasarnya koperasi adalah menghimpun orang bukan menghimpun modal, tetapi meningkatkan jumlah modal juga penting karena koperasi bergerak di bidang ekonomi. Kemudian apakah dengan meningkatnya jumlah modal akan meningkatkan atau menurunkan sisa hasil usaha, untuk itu perlu adanya suatu penelitian, sehingga dari masalah tersebut terdorong untuk mengadakan penelitian.

\section{KAJIAN PUSTAKA}

\section{Koperasi}

Koperasi merupakan suatu bentuk badan usaha yang jauh berbeda bila dibandingkan dengan badan usaha yang lain, baik tujuan, prinsip dan sejarahnya, sehingga kalau 
membicarakan masalah koperasi pertama-tama harus memperoleh kejelasan tentang apa yang dimaksud dengan koperasi. Kejelasan pengertian koperasi sebagai konsep akan memberikan kemudahan di dalam memahami permasalahanpermasalahan lebih lanjut. Koperasi berasal dari kata co dan operation, co berarti bersama, operation berarti bekerja, jadi kalau digabungkan menjadi cooperation berarti bekerja bersama (Purwanto, 2001: 1). Menurut UU No. 12 tahun 1967, tentang Pokok-Pokok Perkoperasian, mengenai pengertian dan fungsi koperasi adalah: Koperasi Indonesia adalah organisasi ekonomi rakyat yang berwatak sosial, beranggotakan orang-orang atau badan-badan hokum koperasi yang merupakan tata susunan ekonomi sebagai usaha bersama berdasarkan atas asas kekeluargaan.

Ciri-ciri koperasi sebagai berikut:

a. Bukan kumpulan modal tetapi kumpulan orang-orang atau badan hokum.

b. Bekerja sama berdasarkan atas asas kekeluargaan.

c. Kegiatan koperasi harus berdasarkan pada kesadaran anggota.

d. Tujuan koperasi harus benar-benar merupakan kepentingan bersama dari para anggotanya.

Tujuan koperasi adalah:

a. Untuk meningkatkan harkat manusia.

b. Untuk meningkatkan pendapatan mereka yang berkecimpung didalamnya.

c. Untuk memperoleh kemanfaatan, baik sosial maupun ekonomi dari usaha koperasi.

d. Untuk memperoleh keringanan-keringanan fasilitas pemerintah.
Macam-macam koperasi:

a. Koperasi golongan fungsional: Koperasi Pegawai Negeri (KPN), Koperasi Angkatan Darat (KOPAD), KOPAL, KOPUD, KOPAK, KOKAR.

b. Koperasi menurut lapangan usahanya: koperasi konsumsi, koperasi produksi (pertanian, peternakan, perikanan, kerajinan), koperasi simpan-pinjam, koperasi unit desa (KUD).

Sendi-sendi dasar koperasi Indonesia adalah:

a. Sifat keanggotaan yang suka rela dan terbuka untuk setiap warga Indonesia.

b. Rapat anggota merpakan kekuasaan tetinggi sebagai pencerminan demokrasi dalam koperasi.

c. Pembagian sisa hasil usaha diatur menurut jasa masing-masing anggota.

d. Adanya pembatasan bunga atas modal.

e. Mengembangkan kesejahteraan anggota khususnya dan masyarakat pada umumnya.

f. Usaha dan ketatalaksanaanya bersifat terbuka.

g. Swadaya, swakarsa, dan swasembada sebagai pencerminan dari pada dasar percaya pada diri sendiri.

Alat perlengkapan organisasi koperasi, terdiri dari tiga macam yaitu: a. Rapat anggota, b. Pengurus, c. Badan pemeriksa.

\section{Modal}

Modal adalah hak-hak atau tuntutan (claim) atas harta benda (Kusnadi, 2009: 245). Pengertian lain modal adalah: baik yang berupa barang-barang konkrit yang masih ada dalam rumah tangga perusahaan yang terdapat dineraca sebelah debet, maupun yang berupa daya beli 
atau nilai tukar dari barang itu yang tercatat disebelah kredit. Jadi yang tercatat disebelah debet dari neraca tersebut disebut modal konkrit, dan yang tercatat disebelah kredit disebut modal abstrak (Bambang Riyanto, 1990: 9). Macammacam modal:

a. Ditinjau dari bentuknya modal, dapat digolongkan menjadi: modal tetap dan modal lancar.

b. Ditinjau dari asal modal, missal: modal sendiri dan modal asing.

Sumber-sumber modal:

a. Dari dalam koperasi sendiri: simpanan pokok, simpanan wajib, simpanan suka-rela, dan cadangan.

b. Dari luar koperasi, mudah dan lancarnya, besar atau kecilnya modal ekstern ini dapat diperoleh koperasi akan sangat tergantung dari reputasi koperasi tersebut, karena timbulnya kepercayaan dari pihak ketiga untuk memberkan pinjaman-pinjaman, nama koperasilah yang menjadi dasarnya.

Faktor yang mempengaruhi perkembangan modal koperasi : anggota, jangka waktu perputaran modal dan perkembangan usaha.

\section{Sisa Hasil Usaha (SHU)}

Menurut Undang-Undang Koperasi No. 12 tahun 1967, sisa hasil usaha adalah: pendapatan yang diperoleh di dalam satu tahun buku setelah dikurangi dengan penyusutanpenyusutan dan biaya-biaya dari tahun buku yang bersangkutan. Sumber-sumber sisa hasi usaha bisa diperoleh dari kegiatan usaha koperasi dan dari luar usaha koperasi. Pembagian sisa hasil usaha digunakan sebagai: cadangan koperasi, untuk anggota, dana pengurus, dana karyawan, dana pendidikan, dana sosial dan dana untuk pengembangan daerah kerja. Sisa hasil usaha yang diperoleh oleh koperasi dari pelayanan terhadap pihak ketiga penggunaanya sama dengan sisa hasil usaha yang diperoleh melalui pelayanan terhadap anggota, bedanya hanya terletak bila sisa hasil usaha yang diperoleh di luar usaha koperasi ini tidak boleh dibagikan kepada anggota, sebab bagian dari sisa hasil usaha ini bukan diperoleh melalui jasa anggota.

\section{HASIL DAN PEMBAHASAN}

Populasi yang digunakan dalam penelitian ini adalah seluruh pengurus ditambah dengan karyawan KPN Keluarga Sehati SMKN-2 Palangkaraya. Data yang diperlukan dalam penelitian ini adalah, data primer (pos-pos transaksi dalam neraca akhir yang ada hubungannya dengan jumlah perkembangan modal dan sisa hasil usaha), dan data sekunder (laporan-laporan pengurus pada akhir periode mengenai neraca akhir yang berkaitan dengan perkembangan jumlah modal dan sisa hasil usaha). Dalam penelitian ini penulis menggunakan dua macam teknik pengumpulan data yaitu: intervieu dan dokumentasi. Analisa data atau pengolahan datanya menggunakan dua tahap yaitu: tahap perhitungan dan tahap penyelesaian. Teknik analisa yang dipakai adalah teknik product moment dari Karl Pearson, sedangkan pengolahan derajad korelasinya dengan perbandingan antara korelasinya yang diperoleh atau yang dicari " $r$ ". Bilaman " $r$ " lebih besar dari nilai $r$ kritik maka signifikan. Dengan nilai signifikan kita akan menolak Ho dan menerima $\mathrm{Hi}$, yang didasarkan atas taraf signifikansi sebesar $5 \%$ yang terdapat dalam table nilai ' $r$ " product moment. Untuk mengetahui hasil 
analisa, maka telah ditetapkan ukuran tingkat korelasi antara variabel $x$ dan $y$ sebagai berikut:

$$
\begin{array}{lll}
0,00-0,20 & \text { Korelasi rendah sekali } \\
0,20-0,40 & \text { Korelasi rendah tetapi ada } \\
0,40-0,70 & \text { Korelasi sedang } \\
0,70-0,90 & \text { Korelasi tinggi } \\
0,90-1,00 & \text { Korelasi tinggi sekali }
\end{array}
$$

Sutrisno Hadi. (1986). Statistik II. Yogyakarta: Yayasan Badan Penerbit Gajah Mada.

Sutrisno Hadi. (1986). Metodologi research II. Yogyakarta: Yayasan Badan Penerbit Gajah Mada.

\section{KESIMPULAN}

1. Perkembangan modal di KPN Keluarga Sehati SMKN-2 Palangkaraya, mulai tahun 2005-2012 mengalami kenaikan pada tiaptiap tahunnya.

2. Perkembangan sisa hasil usaha di KPN Keluarga Sehati SMKN-2 Palangkaraya, mulai tahun 2005-2012 mengalami kenaikan dan penurunan pada tiap-tiap tahunnya.

3. Hubungan antara perkembangan jumlah modal dengan perkembangan jumlah sisa hasil usaha di KPN Keluarga Sehati SMKN-2 Palangkaraya tidak ada hubungannya, ini dikarenakan pengurus lebih mengutamakan kesejahteraan anggota dari pada mencari keuntungan.

\section{DAFTAR PUSTAKA}

Arifin Chaniago. (1984). Perkoperasian Indonesia. Bandung: Angkasa.

Bambang Riyanto. (1984). Dasar-dasar pembelanjaan perusahaan. Yogyakarta: Yayasan Badan Penerbit Gajah Mada.

Karto Saputro. (1987). Koperasi Indonesia yang berdasarkan Pancasila dan UUD 1945. Jakarta: Bina Aksara. 